\title{
Determination of L-Ascorbic Acid in Milk by Ultra-High-Performance Liquid Chromatography Coupled to Tandem Mass Spectrometry Analysis
}

\author{
Caroline D. Zappielo, ${ }^{\circledR a}$ Antonio E. Nicácio, ${ }^{a}$ Luciana P. Manin, ${ }^{b}$ Liane Maldaner ${ }^{a}$ and \\ Jesuí $V$. Visentainer*,a,b \\ ${ }^{a}$ Departamento de Química, Universidade Estadual de Maringá (UEM), \\ 87020-900 Maringá-PR, Brazil \\ ${ }^{b}$ Programa de Pós-Graduação em Ciências de Alimentos, Universidade Estadual de Maringá (UEM), \\ 87020-900 Maringá-PR, Brazil
}

\begin{abstract}
This study provides a fast, accurate and reproducible method for L-ascorbic acid (L-AA) determination in milk samples by ultra-high-performance liquid chromatography coupled to tandem mass spectrometry (UHPLC-MS/MS). A small volume of a low toxicity organic solvent (ethanol) was used for degreasing and deproteinization steps. Ethylenediaminetetraacetic acid disodium salt (EDTA) and formic acid were used as stabilizing agents. The method was successfully validated in terms of linearity, limit of detection (LOD), limit of quantification (LOQ), accuracy, and inter/intra-day precision and applied in raw and processed milk samples. Good linearity $\left(r^{2}>0.9915\right)$ and low LOD and LOQ, 1.5 and $5.0 \mu \mathrm{g} \mathrm{L}-1$, respectively, were obtained. The recoveries for 500 and $1000 \mu \mathrm{g} \mathrm{L}^{-1}$ spikes were higher than $90 \%$ and the precision values expressed in terms of relative standard deviation (RSD) were $\leq 6.8 \%$. For the first time, the determination of L-AA in a $500 \mu \mathrm{g} \mathrm{L}^{-1}$ concentration range was reported for milk samples.
\end{abstract}

Keywords: vitamin C, UHPLC-MS/MS, milk, validation

\section{Introduction}

Milk has been the most consumed food throughout the world. In 2015, global per capita dairy consumption was estimated at $111.3 \mathrm{~kg}$. In addition, milk has great economic and social relevance, as the dairy industry employs millions of people and is an important source of income in the global economic scenario. ${ }^{1,2}$ Nutritionally, milk is an important source of macro and micronutrients, e.g., proteins, lipids, carbohydrates, vitamins and minerals, as well as bioactive compounds such as antioxidants. Among the antioxidants that can be found in milk samples, vitamin $\mathrm{C}$ is one of the most important for the proper functioning of an organism, and furthermore, diet is the only source of this vitamin for humans. ${ }^{3}$

L-Ascorbic acid (L-AA) is the biologically active form of vitamin $\mathrm{C}$, the general term used to name a set of compounds that also exhibit the biological activity of L-AA, such as L-dehydroascorbic acid (L-DHA) and other oxidation products, which can be readily converted

*e-mail: jesuiv@gmail.com to L-AA. Chemically, due to the two hydroxyl groups present in the L-AA structure, L-AA is reversibly oxidized and transformed into L-DHA. ${ }^{3}$ L-DHA also has biological activity, but in milk and milk derivatives it accounts for less than $10 \%$ of the total vitamin $\mathrm{C}$ content. Moreover, L-DHA is irreversibly converted to diketogulonic acid in a later oxidative process. ${ }^{4}$

L-AA is classified as a hydrophilic antioxidant and acts as an electron donor in various metabolic biochemical reactions. It reacts with oxidizing radicals and other oxidizing compounds, such as hydroxyl radicals, superoxide anions and hypochlorous acid, thus protecting the organism from oxidative stress. ${ }^{5}$ In addition, L-AA interacts synergistically since it regenerates the lipophilic antioxidant $\alpha$-tocopherol by reducing the tocopheryl radical, as well as acting as a cofactor of enzymes in collagen biosynthesis and assisting iron absorption from non-heme sources. Thus, L-AA may be considered a biomarker of oxidative stress in biological samples, as well as a biomarker of storage period to ensure the quality of food. ${ }^{6,7}$

There are several factors that induce L-AA oxidation, such as reactive oxygen species (peroxide $\left(\mathrm{H}_{2} \mathrm{O}_{2}\right)$, 
superoxide $\left(\mathrm{O}_{2}{ }^{\bullet-}\right)$ or hydroxyl radical $\left.\left(\mathrm{OH}^{\bullet}\right)\right)$, enzymatic reactions, metal ions, alkaline $\mathrm{pH}$ and high temperatures. ${ }^{3}$ Due to the labile nature of vitamin $\mathrm{C}$, light, $\mathrm{pH}$ and temperature should be controlled during the sample preparation step to avoid L-AA oxidation. ${ }^{8,9}$ Furthermore, several studies have reported that concentration is also a factor that influences the stability of L-AA. Higher concentrations ensure greater stability of L-AA; on the other hand, there is a significant decrease in stability for concentrations below $0.1 \mathrm{mg} \mathrm{L}^{-1} .^{10,11}$

For L-AA determination in milk samples, in addition to the labile nature of vitamin $\mathrm{C}$, additional steps, such as degreasing and deproteinization, are necessary during sample preparation due to the high concentration of lipids and proteins in milk samples and the water-soluble characteristic of vitamin C. ${ }^{12-14}$ Several studies have reported the use of vigorous centrifugation followed by the addition of an acidic solution, such as metaphosphoric acid (MPA), perchloric acid (PCA) or trichloroacetic acid (TCA), for milk sample degreasing and deproteinization. ${ }^{6,12,15}$ Organic solvents, such as ethanol, acetone and acetonitrile, have also been reported as protein precipitating agents in milk and other samples. ${ }^{14,16-19}$

Several analytical methods have been reported for the determination of vitamin C, e.g., enzymatic, ${ }^{20}$ spectrophotometric ${ }^{21}$ and separation techniques such as high-performance liquid chromatography (HPLC), which provide more accurate results. HPLC has been used extensively for L-AA determination in various foods, ${ }^{7,8,22-25}$ including milk. ${ }^{6,12,26}$ Compared to conventional HPLC, the enhanced sensitivity and separation power of ultra-high-performance liquid chromatography (UHPLC) reduces the time and cost of the analysis, which is becoming increasingly important in liquid chromatography applications. ${ }^{27}$ However, there are few UHPLC methods dedicated to L-AA determination in foods, ${ }^{27,28}$ and UHPLC coupled to tandem mass spectrometry (UHPLC-MS/MS) has not yet been used for L-AA determination in milk samples to the best of our knowledge.

Thus, this work aimed to develop a fast, low cost, low toxicity and low oxidative UHPLC-MS/MS analytical method for L-AA determination in milk samples. In addition, the developed method was applied to ultra-high temperature (UHT), pasteurized and raw milk samples.

\section{Experimental}

Standards, solvents and reagents

A $99.7 \%$ purity ascorbic acid standard was purchased from Sigma-Aldrich (Saint Louis, MO, USA). HPLC-grade methanol, ethanol and acetonitrile were purchased from Sigma-Aldrich (Saint Louis, MO, USA). Formic acid, used in the mobile phase and in the extraction procedure, was purchased from Sigma-Aldrich (Saint Louis, MO, USA). Ethylenediaminetetraacetic acid disodium salt (EDTA) was obtained from Fmaia (Belo Horizonte, MG, Brazil). The ultrapure Milli-Q water was obtained from a Milli-Q ultrapure water purification system (Bedford, MA, USA).

A stock standard solution of $1000 \mathrm{mg} \mathrm{L}^{-1}$ of L-AA was prepared daily in water acidified with $0.1 \%$ formic acid. The work standard solutions were prepared by appropriately diluting the stock solution in ethanol acidified with $0.1 \%$ formic acid. All these solutions were stored in a refrigerator at $-18{ }^{\circ} \mathrm{C}$ and protected from light.

\section{Milk samples}

Different commercial milk samples were purchased

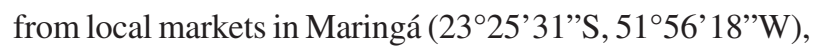
PR, Brazil, including UHT and pasteurized whole (3\% milk fat) and skim milk (0-1\%). Raw (unpasteurized) milk samples were also purchased from local milk producers (Maringá, PR, Brazil). The analyses were carried out immediately after opening the packages for the commercial milk samples and on the day collected for the raw milk samples.

For the method development, a sample of pasteurized whole milk, after degradation of L-AA (blank sample), was used. The blank sample was obtained by sonicating $100 \mathrm{~mL}$ of pasteurized whole milk in an ultrasonic bath, Schuster L200 (Santa Maria, Brazil), at $60{ }^{\circ} \mathrm{C}$ for $5 \mathrm{~h}$. After this pre-treatment, it was not possible to distinguish between the analyte and noise signals.

\section{Study of the extraction procedure}

The procedure for extracting L-AA from milk samples was studied according to the parameters shown in Figure 1. For these experiments, $400 \mu \mathrm{L}$ of the whole pasteurized milk sample (blank sample) was transferred to a $2.0 \mathrm{~mL}$ Eppendorf tube refrigerated in an ice bath $\left(4^{\circ} \mathrm{C}\right)$. Then, $1 \mathrm{mmol} \mathrm{L}^{-1}$ of a $60 \mathrm{mmol} \mathrm{L}^{-1}$ EDTA solution and 800, 1000 or $1200 \mu \mathrm{L}$ of the extracting solvent acidified with $0.1 \%$ formic acid $\left(\mathrm{v} \mathrm{v}^{-1}\right)$ (ethanol or acetonitrile) were added to the tube. The mixtures were shaken for $0.5,1.0$ or $1.5 \mathrm{~min}$ with a Phoenix Luferco AP56 vortex (Araraquara, SP, Brazil) and immediately centrifuged for 3,5 or $10 \mathrm{~min}$ at $4000 \times \mathrm{g}$ in a MSE Sanyo Harrier 18/80R centrifuge (London, UK, England). Approximately $1 \mathrm{~mL}$ the supernatant was collected and filtered through a polytetrafluoroethylene (PTFE) syringe filter (13 mm diameter and $0.22 \mu \mathrm{m}$ pore) 
before UHPLC-MS/MS analysis. The entire extraction procedure was performed in an environment protected from light.

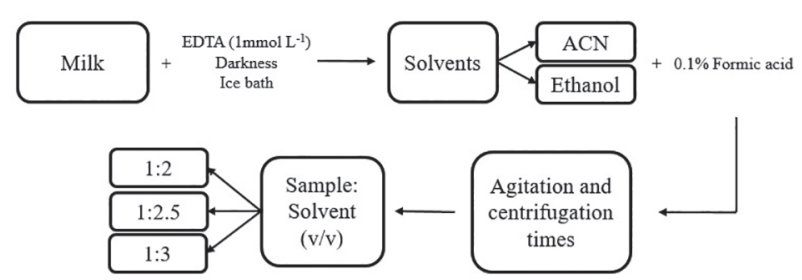

Figure 1. The parameters evaluated in the L-AA in milk samples extraction procedure study.

\section{Proposed extraction procedure}

The validated extraction procedure for L-AA from milk samples was as follows: $400 \mu \mathrm{L}$ of the whole pasteurized milk sample (blank sample) was transferred to a $2.0 \mathrm{~mL}$ Eppendorf tube refrigerated in an ice bath $\left(4^{\circ} \mathrm{C}\right)$. $1 \mathrm{mmol} \mathrm{L}{ }^{-1}$ of a $60 \mathrm{mmol} \mathrm{L}^{-1}$ EDTA solution and $800 \mu \mathrm{L}$ of ethanol acidified with $0.1 \%$ formic acid $\left(\mathrm{v} \mathrm{v}^{-1}\right)$ were added to the tube. The mixtures were shaken for $0.5 \mathrm{~min}$ with a vortex and immediately centrifuged for $5 \mathrm{~min}$ at $4000 \times \mathrm{g}$. Then, approximately $1 \mathrm{~mL}$ the supernatant was collected and filtered through a PTFE syringe filter before UHPLC-MS/MS analysis. The entire extraction procedure was performed in an environment protected from light.

\section{UHPLC-MS/MS analysis}

Chromatographic analyses were carried out using a UHPLC, Acquity H-CLASS (Waters, Milford, MA, USA), coupled to a Xevo TQD triple-quadrupole mass spectrometer equipped with an electrospray (ESI) source Waters Z spray ${ }^{\mathrm{TM}}$ (Milford, MA, USA). Chromatographic separation was performed using a Waters $1.7 \mu \mathrm{m}$ Acquity UPLC $^{\circledR}$ BEH C18 column $(50 \mathrm{~mm} \times 2.1 \mathrm{~mm}$ i.d. $)$ and a mobile phase flow rate of $0.300 \mathrm{~mL} \mathrm{~min}^{-1}$. The column was kept at $30 \pm 1{ }^{\circ} \mathrm{C}$, and the sample injection volume was $1.5 \mu \mathrm{L}$. The mobile phase was composed of $90 \%$ water and $10 \%$ methanol, both acidified with $0.1 \%$ formic acid and the analysis was carried out using isocratic elution.

MS/MS parameters for the analysis of L-AA were as follows: capillary voltage, $3.0 \mathrm{kV}$; extractor voltage, $3.0 \mathrm{~V}$; source temperature, $130^{\circ} \mathrm{C}$ and desolvation gas temperature, $550^{\circ} \mathrm{C}$. The ionization source (ESI) was set in the negative ion mode. The cone gas and desolvation gas (both nitrogen) flow rates were set at 50 and $700 \mathrm{~L} \mathrm{~h}^{-1}$, respectively. Argon (99.9\%) from White Martins (Rio de Janeiro, Brazil) was used at a constant pressure of $3.00 \times 10^{-3} \mathrm{mbar}$ as the collision gas. For instrument control, data acquisition, and processing, version 4.1 MassLynx and QuanLynx software (Waters) were used. The mass spectrometer was operated in MS/MS mode using selected reaction monitoring (SRM). The SRM transitions for L-AA, $m / z(174.9 \rightarrow 114.8+86.8)$, were chosen after evaluating the cone voltage and collision energy. The optimized cone voltage was $25 \mathrm{~V}$ for both transitions and the collision energies were 12 and $21 \mathrm{eV}$, respectively. The first transition was used for quantification and the second one for confirmation.

\section{Method validation}

Linearity, limits of detection (LOD) and quantification (LOQ), precision, accuracy and matrix effect were the parameters analyzed during the method validation process according to the European SANTE/11945/2015 guidelines. ${ }^{29}$ Linearity was evaluated using external matrixmatched calibration curves at ten levels of concentration between 5 and $1200 \mu \mathrm{g} \mathrm{L}^{-1}$. The calibration curve was divided into two linear ranges based on these ten L-AA concentration levels. The method accuracy was evaluated through recovery studies by spiking six sample extracts at each of four concentration levels $(100,300,500$ and $\left.1000 \mu \mathrm{g} \mathrm{L}^{-1}\right)$. The precision, intra-day, and inter-day (evaluated on two consecutive days) analyses were carried out at the same concentration levels as the recovery studies and expressed in terms of relative standard deviation (RSD). LOD and LOQ were calculated as the quantity of analyte able to produce a chromatographic peak three and ten times higher, respectively, than the noise of the baseline of the blank sample. The matrix effect (ME) on L-AA determination was calculated (equation 1) by comparing the slopes of the solvent and external matrix-matched calibration curves obtained at the same concentration levels, according to Kaczyński. ${ }^{30}$

$\% \mathrm{ME}=\left(\frac{\text { slope matrix }}{\text { slope solvent }}-1\right) \times 100$

\section{Application}

A total of eighteen commercial milk samples, including three different brands of whole and skim UHT and pasteurized milk and six raw (unpasteurized) milk samples, were analyzed with the proposed method.

\section{Statistical analysis}

Data were presented as the mean and standard deviation (SD). PAST3 software ${ }^{31}$ was used for Tukey's test $(p<0.05)$ analysis. 


\section{Results and Discussion}

\section{Sample preparation study}

The labile nature of L-AA requires a fast sample preparation step and rigorous controlled extraction conditions to limit changes caused by factors such as light, temperature, $\mathrm{pH}$ and the presence of metals.

The influence of light on the stability of L-AA was studied by Iwase $^{10}$ and the results showed that the concentration of L-AA decreased approximately $20 \%$ after $1 \mathrm{~h}$ of light exposure. For this reason, amber glass and aluminum foil are recommended during the sample preparation step and L-AA storage. The effects of temperature on the stability of L-AA have been widely studied..$^{10,11,32}$ Iwase $^{10}$ evaluated the effect of high temperatures $\left(60\right.$ and $80{ }^{\circ} \mathrm{C}$ ) on L-AA degradation, and the results showed that after $1 \mathrm{~h}$ the initial concentration of L-AA decreased more than $80 \%$. Nováková et al. ${ }^{11}$ evaluated the effect at low temperatures, and the results showed a decrease of $63.5 \%$ of the initial concentration at $4{ }^{\circ} \mathrm{C}$ after $72 \mathrm{~h}$. Thus, controlled low-temperatures are required during the sample preparation step.

Furthermore, L-AA is more stable in the protonated form, so acidic conditions are required to ensure L-AA stability, i.e., preventing oxidation. Studies related to the $\mathrm{pH}$ influence on L-AA stability performed by Chang and Chang, ${ }^{31}$ Iwase $^{10}$ and Nováková et al. ${ }^{11}$ showed that an acid $\mathrm{pH}$ around 2.1 was adequate for sample preparation, ensuring the stability and high recovery of L-AA. Stabilizing agents, such as EDTA which is also usually used as a metal chelator, have often been used to improve the stability of L-AA. The presence of metal ions is a factor that may increase the oxidation of L-AA. ${ }^{3,28}$ Ma et al., ${ }^{12}$ Phillips et al. ${ }^{9}$ and Spínola et al. ${ }^{28}$ used the combination of an acid medium with $1 \mathrm{mmol} \mathrm{L}^{-1}$ of EDTA in their studies for L-AA determination.

Milk is a matrix rich in lipids and proteins and L-AA is a water-soluble molecule. Thus, degreasing and deproteinization of the samples are sample preparation steps which are necessary to allow the accurate determination of L-AA. Several studies report the use of a vigorous centrifugation step to eliminate lipids followed by adding an acid, such as MPA or PCA, ${ }^{6,12}$ for protein precipitation. Organic solvents have also been reported in the literature as deproteinizing and degreasing agents for milk samples. Kim et al. ${ }^{14}$ and Martins-Júnior et al.${ }^{17}$ used $2 \mathrm{~mL}$ of a milk sample and 6 and $5 \mathrm{~mL}$ of acetonitrile, respectively, in their studies and Neves et al..$^{18}$ employed an ethanol:water $\left(1: 1 \mathrm{v} \mathrm{v}^{-1}\right)$ solution and heating $\left(60^{\circ} \mathrm{C}\right.$ for $\left.5 \mathrm{~min}\right)$ for protein precipitation.
In the present work, all sample preparation steps were carried out in an environment sheltered from light and in low-temperature conditions $\left(4^{\circ} \mathrm{C}\right)$. In addition, the organic solvents used in the degreasing and deproteinization steps were acidified with $0.1 \%$ formic acid $\left(\mathrm{v} \mathrm{v}^{-1}\right)(\mathrm{pH}$ ca. 2.0$)$ and $1 \mathrm{mmol} \mathrm{L}^{-1}$ of an EDTA solution was added to the sample. Milli-Q water, acidified with $0.1 \%$ formic acid $\left(\mathrm{v} \mathrm{v}^{-1}\right)$, was used for preparing the L-AA standard solutions and mobile phase solvents.

Milk sample degreasing and deproteinization steps used a stirring step before a vigorous centrifugation step followed by using organic solvents. Ethanol and acetonitrile were investigated, and the extraction efficiency was evaluated in terms of L-AA recovery at a concentration of $500 \mu \mathrm{g} \mathrm{L}^{-1}$. The percentage recovery obtained when ethanol $(90.3 \%)$ was used was significantly higher than with acetonitrile $(52.9 \%)$, as seen in Figure 2. The better extraction power of ethanol is due to its higher polarity when compared to acetonitrile. The presence of the hydroxyl group in its structure attracts L-AA molecules more strongly.

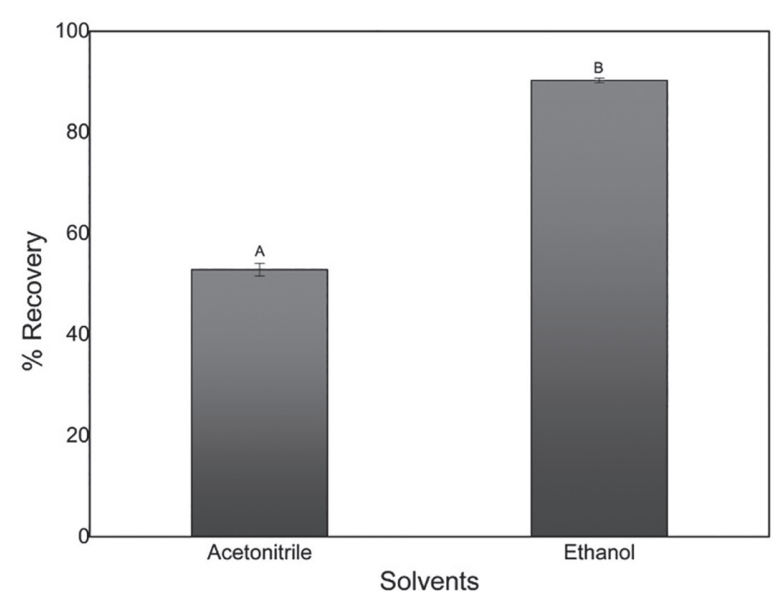

Figure 2. Evaluation of different solvents for the L-AA extraction using a constant volume of $800 \mu \mathrm{L}$. Results expressed as means \pm RSD of three replicates $(n=3)$. Values with different uppercase letters are significantly different $(p<0.05)$ by Tukey's test.

Once the extraction solvent is defined, the evaluation of the influence of the sample:solvent ratio on the extraction efficiency was carried out, keeping the sample volume constant $(400 \mu \mathrm{L})$ and varying the solvent volume (ethanol) at three levels: 800, 1000 and $1200 \mu \mathrm{L}$, considering the respective dilutions of 3.33, 3.50 and 4.00 times. Lower ethanol volumes were not evaluated because insufficient volumes of supernatant $(<1 \mathrm{~mL})$ were obtained. Figure 3 shows that the extraction efficiency decreased with increasing extraction solvent volume. When $800 \mu \mathrm{L}$ of ethanol was used, a $90.4 \%$ recovery percentage was obtained, while recovery values of 76.2 and $69.3 \%$ were obtained for 1000 and $1200 \mu \mathrm{L}$, respectively. Thus, ethanol 
as the extraction solvent in a proportion of $1: 2 \mathrm{v} \mathrm{v}^{-1}$ (sample:solvent), was chosen for the L-AA from milk samples extraction step.

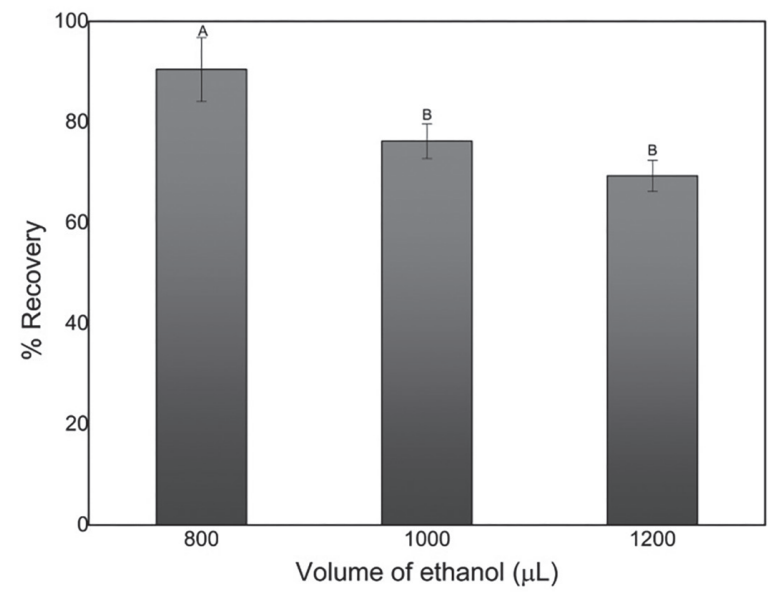

Figure 3. Evaluation of different volumes of the extraction solvent (ethanol). Results expressed as means \pm RSD of four replicates $(n=4)$. Values with different uppercase letters are significantly different $(p<0.05)$ by Tukey's test.

Finally, under the previously established conditions, the influence of sample stirring and centrifugation times on the extraction efficiency were also evaluated. Sample stirring times of $0.5,1.0$ and $1.5 \mathrm{~min}$ were evaluated, however, no significant differences in L-AA recovery were

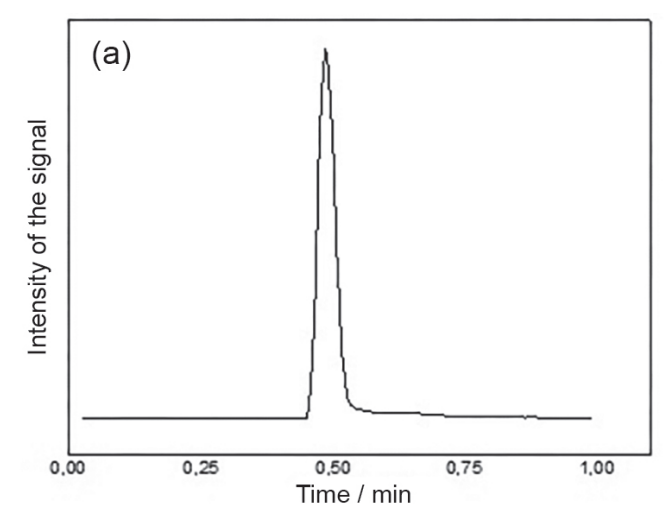

observed. Thus, 0.5 min was established as the optimal stirring time. The centrifugation time was established as the minimum time required for the total separation between the precipitate and the supernatant solution. It was observed that a complete separation without L-AA degradation was obtained with a centrifugation time of $5 \mathrm{~min}$. At lower centrifugation times the supernatant remained cloudy.

\section{Method validation}

After evaluating the analysis conditions for L-AA in the UHPLC-MS/MS system and studying the extraction method, the validation process was performed. For this, linearity, LOD, LOQ, accuracy, precision and ME were the validation parameters evaluated. Tables 1 and 2 summarize the method validation data. Chromatograms of a standard solution of L-AA and a blank milk sample fortified with L-AA are shown in Figure 4. In both chromatograms clearly defined peaks, with retention times of $0.47 \mathrm{~min}$, and a stable baseline can be observed.

An external standardization method at ten concentration levels $(5,10,50,100,200,300,500,700,1000$ and $1200 \mu \mathrm{g} \mathrm{L}^{-1}$ ) was used to determine the linearity. As presented in Table 1, the method developed showed good linearity for all linear ranges with correlation coefficients higher than 0.99 . The proposed method showed LOD

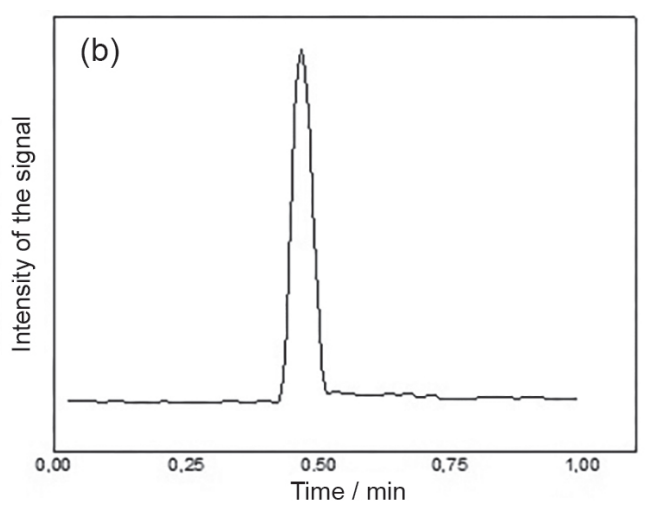

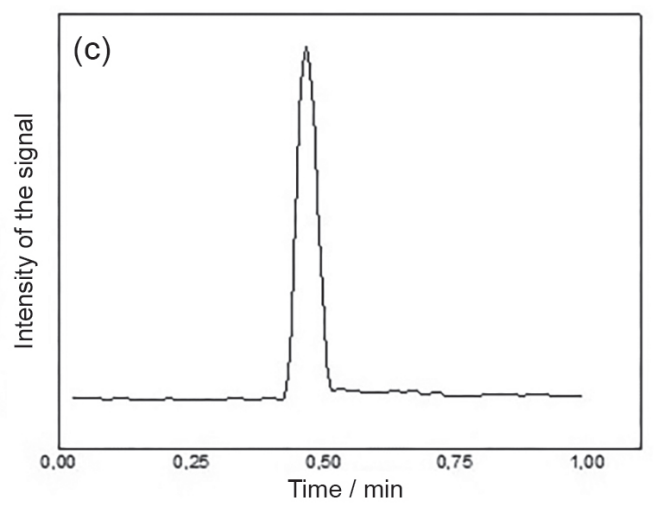

Figure 4. Chromatograms of (a) standard $500 \mu \mathrm{g} \mathrm{L}^{-1}$ solution of L-AA; (b) blank milk sample fortified with $500 \mu \mathrm{g} \mathrm{L}{ }^{-1}$ of L-AA; (c) sample of raw milk. 
Table 1. Linearity, LOD and LOQ of the developed method

\begin{tabular}{lccccc}
\hline Compound & Linear range $/\left(\mu \mathrm{g} \mathrm{L}^{-1}\right)$ & Linear regression $(y=\mathrm{a} x+\mathrm{b})$ & $\mathrm{r}$ & $\mathrm{LOD} /\left(\mu \mathrm{g} \mathrm{L}^{-1}\right)$ & $\mathrm{LOQ} /(\mu \mathrm{g} \mathrm{L}-1)$ \\
\hline & $5-1200$ & $y=\left(1.74 \pm 1.04 \times 10^{-10}\right) x-(16.38 \pm 0.51)$ & 0.9956 & & \\
L-Ascorbic acid & $5-300$ & $y=\left(1.55 \pm 5.53 \times 10^{-6}\right) x+(10.07 \pm 0.25)$ & 0.9962 & 1.5 & 5 \\
& $300-1200$ & $y=\left(1.83 \pm 3.00 \times 10^{-4}\right) x-(91.93 \pm 0.33)$ & 0.9915 & & \\
\hline
\end{tabular}

r: correlation coefficient; LOD: limit of detection; LOQ: limit of quantification; results expressed as means \pm SD (standard deviation) of three replicates $(\mathrm{n}=3$ ).

Table 2. Recovery and precision (intra-day and inter-day) of the developed method

\begin{tabular}{|c|c|c|c|c|c|c|c|c|c|}
\hline \multirow{2}{*}{ Compound } & \multicolumn{4}{|c|}{ Recovery / \% } & \multicolumn{4}{|c|}{ Inter-day precision (RSD) / \% } & \multirow{2}{*}{$\begin{array}{c}\text { Matrix } \\
\text { effect / \% }\end{array}$} \\
\hline & $\mathrm{F} 1$ & $\mathrm{~F} 2$ & F3 & F4 & $\mathrm{F} 1$ & $\mathrm{~F} 2$ & F3 & F4 & \\
\hline L-Ascorbic acid & $32.6(11.0)$ & $59.9(3.3)$ & $90.6(6.8)$ & $95.0(5.7)$ & 5.3 & 10.5 & 2.0 & 1.1 & -63.3 \\
\hline
\end{tabular}

$\mathrm{F} 1: 100 \mu \mathrm{g} \mathrm{L}{ }^{-1} ; \mathrm{F} 2: 300 \mu \mathrm{g} \mathrm{L}{ }^{-1}$; F3: $500 \mu \mathrm{g} \mathrm{L}{ }^{-1} ; \mathrm{F} 4: 1000 \mu \mathrm{g} \mathrm{L}{ }^{-1}$; recovery and precision values (intra and inter-day) values obtained analyzing six replicates at each concentration $(n=6)$; intra-day values expressed as relative standard deviation (RSD) are given in parentheses.

and LOQ values of 1.5 and $5 \mu \mathrm{g} \mathrm{L} \mathrm{L}^{-1}$, respectively, which were satisfactory to quantify the target compound at the concentration levels found in the milk samples.

Accuracy was determined by means of recovery studies at four concentration levels, 100, 300, 500 and $1000 \mu \mathrm{g} \mathrm{L}^{-1}$, with six replicates at each of the levels. The two lower concentration levels were useful to identify the reliability limit of the method since L-AA instability increases with decreasing L-AA concentration. At concentration levels of 100 and $300 \mu \mathrm{g} \mathrm{L}^{-1}$ recoveries below $60 \%$ were obtained, as shown in Table 2. For the two higher concentration levels studied, 500 and $1000 \mu \mathrm{g} \mathrm{L}-1$, recoveries of 90.6 and $95.0 \%$ were obtained, respectively.

The precision was calculated in terms of intra-day and inter-day precision and expressed in terms of relative standard deviation (RSD). RSD values $<11 \%$ were obtained for all concentration levels evaluated, as seen in Table 2.

The developed method presented a matrix effect value of $-63.3 \%$ (Table 2), which indicates the suppression of the analyte signal caused by the matrix. For this reason, the quantitative analysis was performed by means of a matrix-matched calibration to compensate for the matrix effect caused by the co-extracted interferences.

The proposed method was considered adequate, according to the figures of merit obtained. Thus, it can be employed successfully in the analysis of cow milk. Table 3 presents a comparison between the results obtained in this work with data of other similar chromatographic analyzes of L-AA. In general, the proposed method showed higher sensitivity and accuracy than most other studies, with the reduction of the analysis time and the lowest values of LOD and LOQ than the others.

\section{Application of method}

Due to the labile nature of L-AA, handling, processing and storage may affect the degree of L-AA oxidation, thus influencing the amount of L-AA present in different types of milk. In addition, the amount of L-AA in milk is dependent on lactating dairy cow diets, which can lead to significant variations in the L-AA amounts in milk samples, as presented in Table 4 .

In the present study, the developed method was applied to eighteen milk samples, including UHT and pasteurized whole milk (3\% milk fat) and skim milk (0-1\%) samples and raw (unpasteurized) milk samples.

Comparing the amounts of L-AA found in the raw milk samples to the commercial milk samples (UHT and pasteurized) (Table 4), the amounts found in the raw milk samples were around three and four times higher than the amounts found in whole UHT and pasteurized milk samples, respectively. On the other hand, in the pasteurized skim milk samples, the amounts of L-AA found were lower than the LOQ, and in the UHT skim milk samples amounts in the range of four to ten times lower than the raw milk samples were found. These results suggest that industrial processing and storage conditions, especially temperature, oxygen and light, may affect the amount of L-AA in the final product. The lower amounts found for the skim milk samples (UHT and pasteurized) can be attributed to the skimming process (extra processing step) and the type of packaging. The plastic packaging of the pasteurized milk samples allows the passage of light and oxygen, unlike the sterile Tetra Pak® packaging of the UHT milk samples. 
Table 3. Overview of chromatographic methods for determination of L-ascorbic acid

\begin{tabular}{|c|c|c|c|c|c|c|c|c|c|}
\hline Reference & Sample & Sample preparation & Analysis & $\begin{array}{l}\text { Linear range / } \\
\left(\mu \mathrm{g} \mathrm{L}^{-1}\right)\end{array}$ & $\begin{array}{l}\mathrm{LOD} / \\
\left(\mu \mathrm{g} \mathrm{L}^{-1}\right)\end{array}$ & $\begin{array}{l}\mathrm{LOQ} / \\
\left(\mu \mathrm{g} \mathrm{L}^{-1}\right)\end{array}$ & $\begin{array}{c}\text { L-AA recovery } \\
1 \%\end{array}$ & RSD / \% & $\begin{array}{l}\text { Analysis } \\
\text { time / min }\end{array}$ \\
\hline Present work & cow milk & $\begin{array}{l}0.8 \mathrm{~mL} \text { ethanol } 0.1 \% \\
\text { formic acid and } \\
1 \mathrm{mmol} \mathrm{L}^{-1} \mathrm{EDTA}\end{array}$ & $\begin{array}{l}\text { UHPLC- } \\
\text { MS/MS }\end{array}$ & $5-1200$ & 1.5 & 5 & $90.6-95.0$ & $1.1-2.0$ & 1 \\
\hline Frenich et al..$^{22}$ & $\begin{array}{c}\text { food } \\
\text { commodities }\end{array}$ & $\begin{array}{c}5 \mathrm{~mL} \text { of methanol and } \\
25 \mathrm{~mL} \text { of a mixture of } \\
3 \% \mathrm{MPA} \text { and } 8 \% \text { acetic } \\
\text { acid }\end{array}$ & $\begin{array}{l}\text { HPLC- } \\
\text { MS/MS }\end{array}$ & $100-1000$ & 10 & 50 & 85 & 8.7 & 5 \\
\hline $\begin{array}{l}\text { Romeu-Nadal } \\
\text { et al. }{ }^{6}\end{array}$ & human milk & $\begin{array}{c}0.3 \mathrm{~mL} 0.56 \%\left(\mathrm{~m} \mathrm{v}^{-1}\right) \\
\text { MPA }\end{array}$ & HPLC-UV & $500-100000$ & b & b & 95.55 & $3.12-4.07$ & $>12$ \\
\hline Ma et al..$^{12}$ & human milk & $\begin{array}{l}0.5 \mathrm{~mL} \text { of } 15 \% \text { PCA } \\
\left(\mathrm{v} \mathrm{v}^{-1}\right) \text { containing } \\
1 \mathrm{mmol} \mathrm{L}-1 \text { EDTA }\end{array}$ & HPLC-CL ${ }^{c}$ & $88-3520$ & 8.1 & b & $91.8-106.7$ & 4.13 & 14 \\
\hline $\begin{array}{l}\text { Odriozola } \\
\text { et al. } .^{24}\end{array}$ & fruits & $25 \mathrm{~mL}$ of $4.5 \% \mathrm{MPA}$ & HPLC-UV & $50-500$ & 17 & 57 & $93.6-104.4$ & $0.6-3.9$ & $\mathrm{~b}$ \\
\hline Spínola et al. ${ }^{28}$ & $\begin{array}{l}\text { fruits and } \\
\text { vegetables }\end{array}$ & $\begin{array}{l}10 \mathrm{~mL} \text { of a mixture of } \\
3 \% \mathrm{MPA}, 8 \% \text { acetic acid } \\
\text { and } 1 \mathrm{mmol} \mathrm{L}^{-1} \mathrm{EDTA}\end{array}$ & $\begin{array}{l}\text { UHPLC- } \\
\text { PDA }^{\mathrm{d}}\end{array}$ & $50-2000$ & 22 & 67 & $88.9-102.5$ & $0.9-3.9$ & 6 \\
\hline
\end{tabular}

LOD: limit of detection; LOQ: limit of quantification; L-AA: L-ascorbic acid; RSD: relative standard deviation; EDTA: ethylenediaminetetraacetic acid disodium sal; UHPLC-MS/MS: ultra-high-performance liquid chromatography coupled to tandem mass spectrometry; MPA: metaphosphoric acid; HPLC: high performance liquid chromatography; PCA: perchloric acid; ${ }^{a} \mathrm{UV}-$ Vis detector; ${ }^{\mathrm{b}}$ data not described; ${ }^{\mathrm{c}}$ chemiluminescence detector; ${ }^{\mathrm{d}}$ photodiode array detector.

Table 4. Concentration of L-ascorbic acid determined in raw milk and different types of commercial milk samples

\begin{tabular}{|c|c|c|c|c|c|c|}
\hline \multirow{2}{*}{ Compound } & \multicolumn{6}{|c|}{ Milk sample / $\left(\mu \mathrm{g} \mathrm{L}^{-1}\right)$} \\
\hline & \multicolumn{6}{|c|}{ Raw } \\
\hline \multirow{7}{*}{ L-AA } & $5416.0 \pm 2.5^{\mathrm{A}}$ & $7316.7 \pm 3.7^{\mathrm{B}}$ & $7683.4 \pm 2.2^{\mathrm{C}}$ & $6472.3 \pm 6.9^{\mathrm{D}}$ & $6448.5 \pm 3.6^{\mathrm{D}}$ & $5020.7 \pm 2.3^{\mathrm{E}}$ \\
\hline & & Whole UHT & & & Skim UHT & \\
\hline & A & B & $\mathrm{C}$ & A & B & $\mathrm{C}$ \\
\hline & $2587.0 \pm 2.8^{\mathrm{F}}$ & $2258.0 \pm 4.5^{\mathrm{F}}$ & $3342.2 \pm 2.2^{\mathrm{G}}$ & $628.7 \pm 5.0^{\mathrm{H}}$ & $565.3 \pm 2.1^{\mathrm{H}}$ & $1574.5 \pm 5.2^{1}$ \\
\hline & \multicolumn{3}{|c|}{ Whole pasteurized } & \multicolumn{3}{|c|}{ Skim pasteurized } \\
\hline & $\mathrm{D}$ & $\mathrm{E}$ & $\mathrm{F}$ & $\mathrm{D}$ & E & $\mathrm{F}$ \\
\hline & $1771.5 \pm 5.2^{\mathrm{IJ}}$ & $1968.4 \pm 4.2^{\mathrm{FJ}}$ & $1840.6 \pm 4.2^{\mathrm{IJ}}$ & $<\mathrm{LOQ}$ & $<$ LOQ & $<$ LOQ \\
\hline
\end{tabular}

L-AA: L-ascorbic acid; LOQ: limit of quantification; A, B, C, D, E and F: different brands of commercial milk; results expressed as means \pm SD (standard deviation) of six replicates $(n=6)$; results expressed as means \pm RSD of six replicates $(n=6)$; values with different uppercase letters are significantly different $(p<0.05)$ by Tukey's test.

\section{Conclusions}

In the present work, a fast, low cost, low oxidative, accurate and reproducible methodology based on UHPLC-MS/MS was developed, validated and successfully applied for the analysis of L-AA in different milk samples. In the sample preparation step, small sample volumes and a low toxicity organic solvent (ethanol) were used to perform the degreasing and deproteinization of the milk samples with satisfactory efficiency. In addition, the combination of a short analysis time and a fast extraction procedure with the use of stabilizing agents (EDTA and formic acid) ensure the stability of L-AA. The validated method showed good analytical performance for concentration levels in the range of 500 and $1000 \mu \mathrm{g} \mathrm{L}^{-1}$ with recoveries higher than $90 \%$ and $\mathrm{RSD} \leq 6.8$.

The developed method was successfully applied to the analysis of L-AA in raw, pasteurized and UHT milk samples. L-AA was found in all milk samples analyzed, however the amounts varied according to the type of milk. In a general way, the amount of L-AA decreased according to the level of exposure of the milk, i.e., the processing steps and the storage packaging.

Thus, the developed method is a promising alternative for L-AA analysis in milk samples by UHPLC-MS/MS and can be expanded to different milk sources. 


\section{Acknowledgments}

We would like to thank Conselho Nacional de Desenvolvimento Científico e Tecnológico-Brazil (CNPq); Fundação Araucária de Apoio ao Desenvolvimento Científico e Tecnológico do Paraná; and Coordenação de Aperfeiçoamento de Pessoal de Nível Superior-Brazil (CAPES) for support and the scholarship.

\section{References}

1. International Dairy Federation; Bulletin of the International Dairy Federation 481/2015; The World Dairy situation 2015; 2015.

2. Food and Agriculture Organization of the United Nations; http:// www.fao.org/faostat, accessed on September 12, 2018.

3. Nováková, L.; Solich, P.; Solichová, D.; TrAC, Trends Anal. Chem. 2008, 27, 942.

4. Spínola, V.; Llorent-Martínez, E. J.; Castilho, P. C.; J. Chromatogr. A 2014, 1369, 2.

5. Ferin, R.; Pavão, M. L.; Baptista, J.; Clin. Biochem. 2013, 46, 665.

6. Romeu-Nadal, M.; Morera-Pons, S.; Castellote, A. I.; LópezSabater, M. C.; J. Chromatogr. B: Anal. Technol. Biomed. Life Sci. 2006, 830, 41.

7. Burini, G.; J. Chromatogr. A 2007, 1154, 97.

8. Hernández, Y.; Lobo, M. G.; González, M.; Food Chem. 2006, $96,654$.

9. Phillips, K. M.; Tarragó-Trani, M. T.; Gebhardt, S. E.; Exler, J.; Patterson, K. Y.; Haytowitz, D. B.; Pehrsson, P. R.; Holden, J. M.; J. Food Compos. Anal. 2010, 23, 253.

10. Iwase, H.; J. Chromatogr. A 2000, 881, 317.

11. Nováková, L.; Solichová, D.; Pavlovičová, S.; Solich, P.; J. Sep. Sci. 2008, 31, 1634.

12. Ma, L.; Shi, H.; Lian, K.; Diao, Y.; Chen, Y.; Ma, C.; Kang, W.; Food Chem. 2017, 218, 422.

13. Moraes, F. S.; da Costa, M. P.; Silva, V. L. M.; Moreira, R. V. B. P.; de Barros, R. F.; Mársico, E. T.; Conte-Junior, C. A.; Silva, A. C. O.; Food Chem. 2017, 217, 346.

14. Kim, H. J.; Bae, I. K.; Jeong, M. H.; Park, H. J.; Jung, J. S.; Kim, J. E.; Int. J. Anal. Chem. 2015, 2015, ID: 892486.
15. Niero, G.; de Marchi, M.; Masi, A.; Penasa, M.; Cassandro, M.; J. Dairy Sci. 2015, 98, 6014.

16. Biswas, A. K.; Sahoo, J.; Chatli, M. K.; LWT - Food Sci. Technol. 2011, 44, 1809.

17. Martins-Júnior, H. A.; Kussumi, T. A.; Wang, A. Y.; Lebre, D. T.; J. Braz. Chem. Soc. 2007, 18, 397.

18. Neves, L. N. O.; Marques, R.; da Silva, P. H. F.; de Oliveira, M. A. L.; Food Chem. 2018, 258, 337.

19. Niero, G.; Penasa, M.; Currò, S.; Masi, A.; Trentin, A. R.; Cassandro, M.; de Marchi, M.; Food Chem. 2017, 220, 371.

20. Shekhovtsova, T. N.; Muginova, S. V.; Luchinina, J. A.; Galimova, A. Z.; Anal. Chim. Acta 2006, 573-574, 125.

21. Llamas, N. E.; di Nezio, M. S.; Band, B. S. F.; J. Food Compos. Anal. 2011, 24, 127.

22. Frenich, A. G.; Torres, M. E. H.; Vega, A. B.; Vidal, J. L. M.; Bolanos, P. P.; J. Agric. Food Chem. 2005, 53, 7371.

23. Fenoll, J.; Martínez, A.; Hellín, P.; Flores, P.; Food Chem. 2011, $127,340$.

24. Odriozola-Serrano, I.; Hernández-Jover, T.; Martín-Belloso, O.; Food Chem. 2007, 105, 1151.

25. Chebrolu, K. K.; Jayaprakasha, G. K.; Yoo, K. S.; Jifon, J. L.; Patil, B. S.; LWT - Food Sci. Technol. 2012, 47, 443.

26. Moltó-Puigmartí, C.; Permanyer, M.; Castellote, A. I.; LópezSabater, M. C.; Food Chem. 2011, 124, 697.

27. Klimczak, I.; Gliszczynska-wiglo, A.; Food Chem. 2015, 175, 100.

28. Spínola, V.; Mendes, B.; Câmara, J. S.; Castilho, P. C.; Anal. Bioanal. Chem. 2012, 403, 1049.

29. SANTE/EU; Guidance Document on Analytical Quality Control and Method Validation Procedures for Pesticides Residues Analysis in Food and Feed; SANTE/11945/2015, vol. 11945; 2015, p. 1-42.

30. Kaczyński, P.; Food Chem. 2017, 230, 524.

31. Hammer, Ø.; Harper, D. A. T.; Ryan, P. D.; Palaeontol. Electron. 2001, $4,9$.

32. Chang, M. L.; Chang, C. M.; J. Pharm. Biomed. Anal. 2003, 33,617 .

Submitted: October 8, 2018

Published online: January 11, 2019 